\title{
Neuroendocrine liver metastasis from the small intestine: Is surgery beneficial for survival?
}

\author{
Andreas Selberherr ${ }^{{ }^{*}}$ (D), Simon Freermann ${ }^{1}$, Oskar Koperek², Martin B. Niederle ${ }^{3}$, Philipp Riss ${ }^{1}$, \\ Christian Scheuba ${ }^{1}$ and Bruno Niederle ${ }^{1}$
}

\begin{abstract}
Background: Neuroendocrine neoplasia of the small intestine (siNEN) are frequently diagnosed with liver metastases. The impact of the presence of liver metastases on overall survival and the necessity of surgery for liver metastasis is discussed controversially. The aim of this study is to evaluate and compare the overall long-term survival of patients with siNENs with and without liver metastasis at initial diagnosis and the possible benefit of surgical treatment as compared to active surveillance of metastases. 123 consecutive patients with siNENs were treated between 1965 and 2016. All clinical and histological records were reevaluated including analysis of the proliferation rates in all specimens. The 1-, 5-, 10- and 20-year overall survival was estimated by Kaplan-Meier analysis for patients with and without liver metastasis and according to the type of treatment (surgical vs. surveillance) of liver metastases if present.
\end{abstract}

Results: The 1-, 5-, 10- and 20-year overall survival rate was $89.0 \%, 68.4 \%, 52.8 \%$ and $31.0 \%$ in patients without and $89.5 \%, 69.5 \%, 33.2 \%$ and $3.6 \%$ in those with liver metastases. No statistically significant differences were observed comparing the two groups. Within the group of patients with liver metastases, the type of treatment (surgical vs. surveillance) was in favor of patients undergoing surgery. Multivariate analysis showed that the presence of liver metastases upon diagnosis was an individual risk factor associated with worse survival.

Conclusion: The presence of liver metastasis at initial diagnosis does not have a statistically significant influence on survival. Surgery for hepatic metastasis seems to show a benefit for overall survival and may be indicated especially in patients symptomatic due to high tumor burden and serotonin hypersecretion to reduce hormone activity.

Keywords: Neuroendocrine tumors, Neuroendocrine neoplasia, Livermetastasis, NET, NEN, Small intestine

\section{Background}

Neuroendocrine neoplasia (NEN) of the small intestine (si) are rare tumors with an estimated incidence of 0.29 per $100,000[1,2]$. SiNENs remain asymptomatic for a long time because of the late onset of symptoms which are most commonly unspecific. Elevated levels

\footnotetext{
*Correspondence: andreas.selberherr@meduniwien.ac.at

${ }^{1}$ Section "Endocrine Surgery", Division of General Surgery, Department of Surgery, Medical University, Währinger Gürtel 18-20, 1090 Vienna, Austria

Full list of author information is available at the end of the article
}

of serotonin (5-HT) which correlate with tumor burden may cause carcinoid syndrome that is characterized by diarrhea, flushing, sweating and palpitations $[3,4]$. Diagnosis is frequently made in late stage with/without serotonin related symptoms or due to bowel obstruction caused by the tumor mass [5]. In about $36 \%$ of patients, metastases are already present at initial diagnosis [6].

In the early stages of disease (I-III A (=NO, M0)] the treatment of choice is radical surgery of the primary and lymph nodes. This treatment is related to an excellent 5 -year disease specific survival of $100 \%$. In stage III B and original author(s) and the source, provide a link to the Creative Commons licence, and indicate if changes were made. The images or other third party material in this article are included in the article's Creative Commons licence, unless indicated otherwise in a credit line to the material. If material is not included in the article's Creative Commons licence and your intended use is not permitted by statutory regulation or exceeds the permitted use, you will need to obtain permission directly from the copyright holder. To view a copy of this licence, visit http://creativecommons.org/licenses/by/4.0/. The Creative Commons Public Domain Dedication waiver (http://creativeco mmons.org/publicdomain/zero/1.0/) applies to the data made available in this article, unless otherwise stated in a credit line to the data. 
IV patients' 5 -year survival rates of $97.1 \%$ and $84.8 \%$ are reported $[2,7]$.

The benefit of surgical therapy of liver metastasis is discussed controversially. A recent analysis showed that the type of liver resection (anatomic versus non-anatomic) in patients with M1 disease showed higher rates of recurrence after non-anatomic resection but the type of resection did not affect overall survival [8]. Another analysis of 111 patients found that surgical resection influenced mortality after 5 but not after 10 years [9]. It was the aim of this study to compare survival rates of patients with and without liver metastasis and to investigate whether surgery for hepatic metastasis can improve overall survival.

To our knowledge, this is the first study investigating the reasonability of liver surgery in a big cohort of patients with siNENs over a follow-up period of 20 years.

\section{Methods}

In this study we included all patients who had received surgery for the primary tumor \pm surgery for liver metastases because of a siNEN between 1965 and 2016 at the Division of Surgery, Medical University of Vienna.

Clinical and therapeutic details were documented for all patients. All histological specimens were revised and reclassified by one pathologist, including immune-histochemical analysis of the Ki-67 proliferation index. The grading (G1-G3) was performed according to the current guidelines [10].

Follow-up was performed at the outpatient clinic of the department of surgery following the current ENETS recommendations [11].

\section{Statistics}

Loss of long-term follow-up was documented in 6/123 (4.9\%) patients. These patients were excluded from survival analysis (Table 2). Furthermore, three patients had received a liver transplant, also these patients were regarded as a separate group and not included in the survival analysis ( $\mathrm{n}$ of patients included in the survival analysis $=114$ ).

Additional adjuvant medical treatment (e.g. somatostatin-analogues, mTOR-inhibitors, RTK-inhibitors, livertargeted therapies) was discussed in multidisciplinary tumor board meetings and (if feasible) recommended during follow-up and was performed uniformly in patients of all groups according to progress regarding RECIST criteria or contemporary criteria of the respective era the patient was treated in. Therefore, additional loco-regional treatment after surgery or during surveillance may be regarded the same for all patients and is therefore not discussed in detail.
The survival rates were estimated by Kaplan-Meier analysis for patients with and without liver metastasis and according to the type of treatment of liver metastases (surgical vs. surveillance).

In a sub-analysis the patients with small liver resections ( $\leq 1$ segment, group $2 \mathrm{a}, 15$ patients) were merged into one cohort with patients with liver resections of more than one segment ( $>1$ segment, group $2 \mathrm{~b}, 7$ patients). Details of the subgroups are presented in Table 3.

Survival rates of groups were compared using log-rank tests for the overall survival and cox regression was performed. Statistical significance was considered with a $p<0.05$.

All calculations were done with SPSS Statistics 26.0 and Microsoft Excel 16 for Windows.

\section{Results}

One hundred and twenty-three patients with siNENs of the of the jejunum $(n=22[17.9 \%])$ or ileum $(n=101$ [82.1\%]) were treated at the Division of Surgery, Medical University of Vienna within 50 years (1965 and 2016). Seventy one were male (57.7\%) and 52 (42.3\%) were female (ratio: male:female $=1.37: 1$ ); the mean age was 62 (range: $36-87$ years).

The primary tumors were classified G1 in $94 / 123$ (76.4\%) or low G2 (Ki-67 $\leq 5 \%)$ in 29/123 (23.6\%). No G3 tumors were verified. Multifocality was seen in $40 / 123$ (32.5\%) patients.

In 81/117 (69.2\%) liver metastasis were documented. The distribution of the proliferation index was equal and therefore comparable between patients with and without liver metastases.

The detailed staging of the patients is summarized in Table1.

\section{Overall survival of $\mathrm{M} 0$ and $\mathrm{M} 1$ patients}

The mean follow-up was $121 \pm 49.4$ in group M0 and $86 \pm 7.6$ months in group M1. The overall survival calculation by Kaplan-Meier showed an estimated survival of $176.3 \pm 30.3$ months for patients without liver metastases and $98.1 \pm 8.1$ months for patients with liver metastases (Fig. 1). Although there was a clear trend for better survival in group M0 in the overall comparison with the log rank test, the result marginally did not reach statistical significance $(p=0.051)$. The cumulative $1-, 5-, 10-$ and 20 -year survivals calculated by Kaplan-Meier are summarized in Table 2.

\section{Treatment specific overall survival of M1 patients}

In the sub-analysis the mean overall survival estimated by Kaplan-Meier for patients without surgery for liver-metastases was $88.1 \pm 8.3$ months and $130.7 \pm 18.5$ months for patients who had received liver 
Table 1 Demographics

\begin{tabular}{|c|c|c|}
\hline & & $\begin{array}{l}\text { Total } \\
n=123 / 117^{a}\end{array}$ \\
\hline \multirow[t]{2}{*}{ Gender } & Male & $71(57.7 \%)$ \\
\hline & Female & $52(42.3 \%)$ \\
\hline \multirow[t]{2}{*}{ Localization } & Jejunum & $22(17.9 \%)$ \\
\hline & Ileum & $101(82.1 \%)$ \\
\hline \multirow[t]{2}{*}{ Grading } & G1 & $94(76.4 \%)$ \\
\hline & G2 & $29(23.6 \%)$ \\
\hline \multirow[t]{2}{*}{ Primary tumors } & Solitary & $83(67.5 \%)$ \\
\hline & Multiple & $40(32.5 \%)$ \\
\hline Age (range) & & $62(36 ; 87)$ \\
\hline Stage I-III A & $\mathrm{NO}, \mathrm{MO}$ & $35 / 117^{a}(29.9 \%)$ \\
\hline Stage III B & $\mathrm{N} 1, \mathrm{MO}$ & $1 / 117^{\mathrm{a}}(0.9 \%)$ \\
\hline \multirow[t]{5}{*}{ Stage IV } & N0/N1, M1 & $81 / 117^{\mathrm{a}}(69.2 \%)$ \\
\hline & No liver surgery (surveillance-Group 1) & $53 / 81(65.4 \%)$ \\
\hline & $\begin{array}{l}\text { Liver resection } \leq 1 \text { segment (Group } \\
\text { 2a) }\end{array}$ & $17 / 81(21.0 \%)$ \\
\hline & $\begin{array}{l}\text { Liver resection > } 1 \text { segment (Group } \\
2 \mathrm{~b} \text { ) }\end{array}$ & $8 / 81(9.9 \%)$ \\
\hline & Liver transplantation & $3 / 81(3.7 \%)^{b}$ \\
\hline
\end{tabular}

a 6 patients were lost in long-term follow-up

${ }^{\mathrm{b}}$ Excluded from survival analysis

surgery (Fig. 2). The log rank test shows statistical significance $(p=0.04)$.
The Kaplan-Meier calculation demonstrated a 1-year survival of $86.5 \pm 4.4 \%$ (patients at risk: 49 ) for patients without and $96.0 \pm 3.9 \%$ (patients at risk: 21 ) for patients with liver surgery.

The 5-year and 10-year survival was $68.8 \pm 6.4 \%$ (patients at risk: 33 ) and $24.3 \pm 6.6 \%$ (patients at risk: 9 ) for patients with surveillance, $73.9 \pm 10.2 \%$ (patients at risk: 12 ) and $60.5 \pm 12 \%$ (patients at risk: 6 ) for patients with liver surgery, respectively. The 20-year survival calculations showed that one patient in the group without surgery was still alive. Details, including the sub-analysis according to the extent of surgery are listed in Table 3.

No statistical significance with regard to overall survival was documented comparing group 2a (minor liver surgery) and $2 \mathrm{~b}$ (major liver surgery).

\section{Multivariate analysis}

A cox proportional hazards regression analysis was performed on individual risk factors (presence of liver metastases; grading: G1 vs. G2; multifocality; surgery vs. surveillance) and showed that only the presence of liver metastases at diagnosis was an individual risk factor for worse survival (hazard ratio: 2.371).

\section{Discussion}

Due to a long indolent course, many patients with siNENs are diagnosed in a late, metastasized state. Therefore, not surprisingly, distant metastases were found in

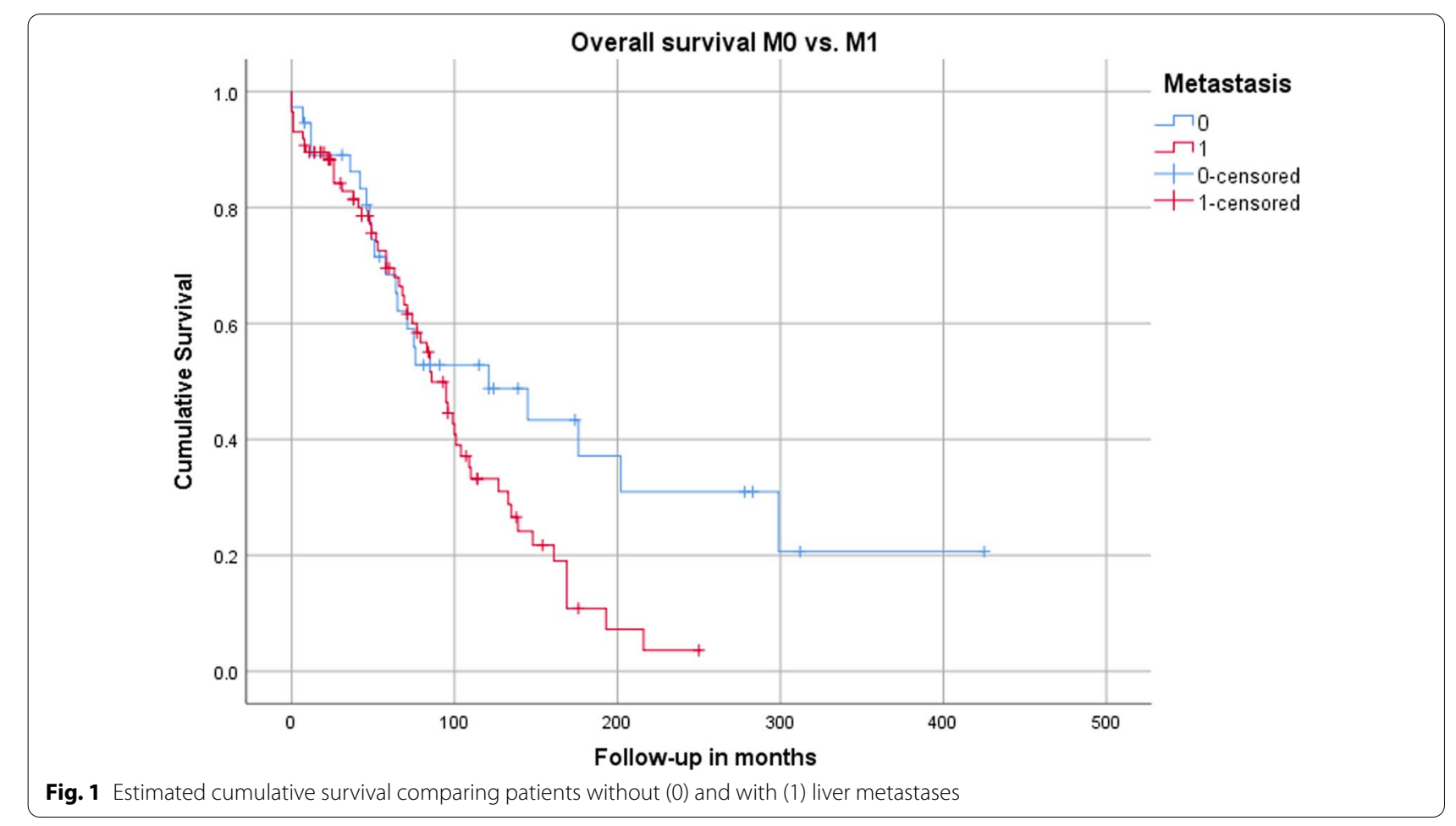


Table 2 Overall 1-, 5-, 10- and 20-year survival; [patients at risk]

\begin{tabular}{llllll}
\hline Metastasis & \multicolumn{4}{l}{ Estimated cumulative survival (Kaplan-Meier) } & \\
\cline { 3 - 6 } & & 1-year & 5-year & 10-year & 20-year \\
\hline M0 & $\mathrm{n}=36 / 117(30.8 \%)$ & $89.0 \pm 5.2 \%[32]$ & $68.4 \pm 7.9 \%[22]$ & $52.8 \pm 8.7 \%[17]$ & $31.0 \pm 10.0 \%[5]$ \\
M1 & $\mathrm{n}=81 / 117(69.2 \%)$ & $89.5 \pm 3.3 \%[76]$ & $69.5 \pm 5.4 \%[46]$ & $33.2 \pm 6.1 \%[17]$ & $3.6 \pm 3.4 \%[1]$ \\
\hline
\end{tabular}

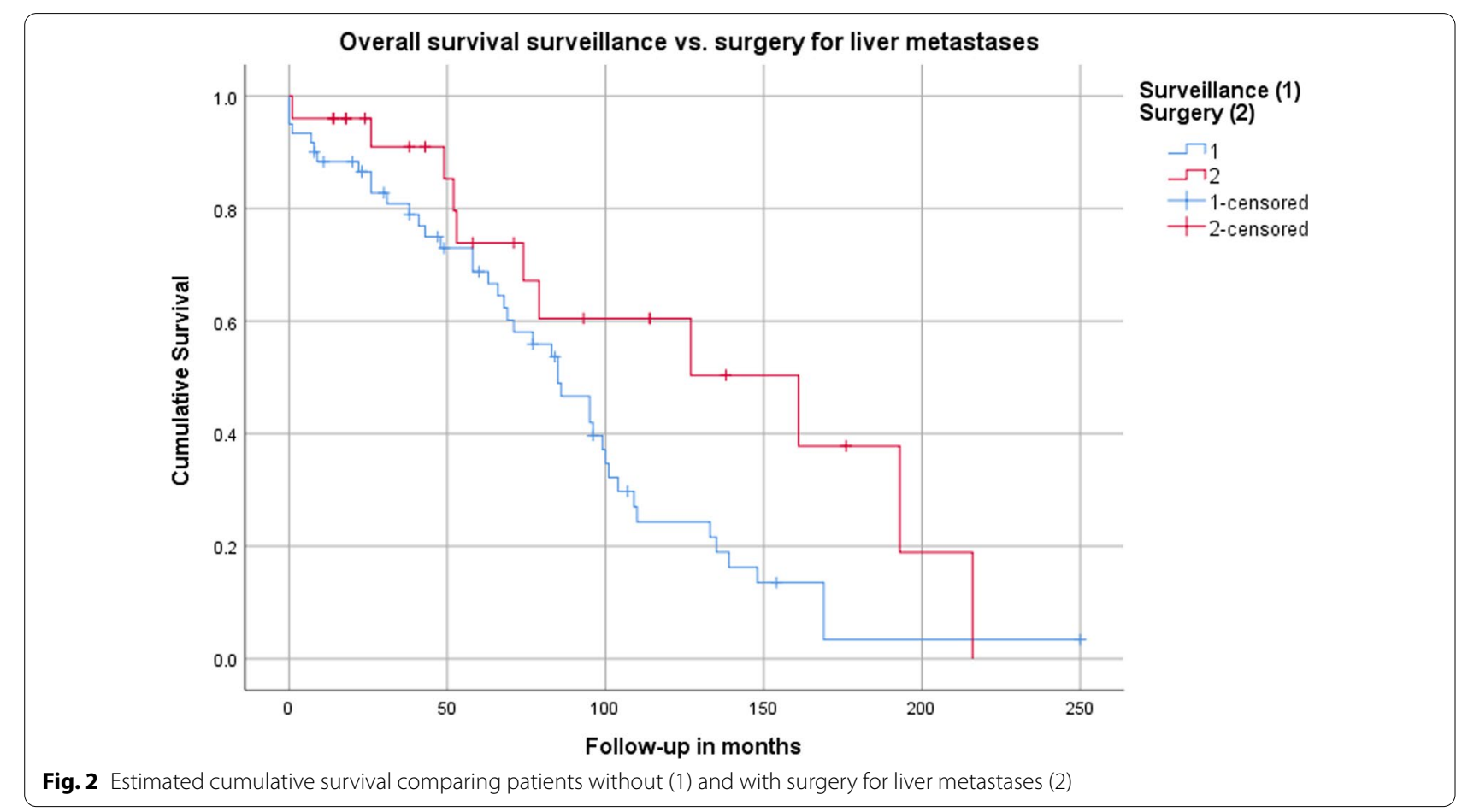

Table 3 Overall 1-, 5-, 10- and 20-year survival regarding treatment of liver metastases; [patients at risk]

\begin{tabular}{lllllll}
\hline Treatment & & \multicolumn{4}{l}{ Estimated cumulative survival (Kaplan-Meier) } \\
\cline { 5 - 7 } & & & 1-year survival & 5-year survival & 10-year survival & 20-year survival \\
\hline Group 1 & Surveillance & $\mathrm{n}=52$ & $86.5 \pm 4.4 \%[49]$ & $68.8 \pm 6.4 \%[33$ & $24.3 \pm 6.6 \%[9]$ & $3.4 \pm 3.2[1]$ \\
Group 2 & Surgery & $\mathrm{n}=22$ & $96.0 \pm 3.9 \%[21]$ & $73.9 \pm 10.2 \%[11]$ & $60.5 \pm 12 \%[6]$ & 0 \\
Subgroup 2a & Minor liver surgery ( $\leq 1$ segment) & $\mathrm{n}=15$ & $94.1 \pm 5.7 \%[14]$ & $76.7 \pm 12.2 \%[6]$ & $63.9 \pm 15.5 \%[3]$ & 0 \\
Subgroup 2b & Major liver surgery (>1 segment) & $\mathrm{n}=7$ & $100 \%\left[7^{\mathrm{a}}\right]$ & $71.4 \pm 17.1 \%[5]$ & $57.1 \pm 18.7 \%[3]$ & 0 \\
\hline
\end{tabular}

a Only one patient remained free of liver-metastases during follow-up

$81 / 117(69.2 \%)$ patients, which is a higher number than reported in a former analysis [6]. Current literature controversially discusses the surgical treatment of (asymptomatic) primary tumor(s) and lymph node metastasis and the influence on prognosis in patients with verified liver metastases [12-15]. However, primary tumors and lymph node metastases may cause bowel obstruction or obstruction of the blood supply of the intestine resulting in life threatening ischemic damage of the intestine
[2]. Therefore, all patients who are included in the current analysis had surgery of the primary tumors and of affected lymph nodes.

Medical treatment with somatostatin analogues is state of the art in stage IV patients $[16,17]$. However the surgical treatment of liver metastases is still an ongoing matter of debate $[18,19]$. Debulking liver surgery may be indicated to reduce serotonin-producing tumor mass in patients who are symptomatic because 
of hormone excess leading to diarrhea with electrolyte deficiency, flushing, sweating, palpitations or Hedinger's syndrome. In current guidelines detailed information is published on systemic therapy [18]. However recommendations for surgery in asymptomatic or minimally symptomatic patients with liver metastasis are lacking $[20,21]$. Recently a benefit of surgery of liver metastasis of neuroendocrine neoplasia of the pancreas was shown in regard to overall survival, however there is little data on siNENs [22]. Moreover, patients with siNENs early demonstrate multiple (in the majority small) bilobar liver metastases and curative surgery is rarely possible [19].

In the current patient cohort patients verified with liver metastasis have a similar 1 - and 5-year overall survival compared to patients with surgically treated regionalized disease (primary tumor removed and lymph node metastases dissected). This may be explained by the slow growth of liver lesions and the good interaction of generalized medical treatment and/or liver-targeted therapies $[18,23,24]$. The estimation of the mean overall survival of patients without liver metastases (176.3 \pm 30.3 months) compared to patients with liver metastases $(98.1 \pm 8.1)$ shows a clear trend in favor of patients with regionalized disease, however statistical significance was not reached $(p=0.051)$. Comparing the 10 -year overall survival of M0 $(52.8 \pm 8.7 \%)$ and M1 patients $(33.2 \pm 6.1 \%)$ a clear trend was documented and multivariate analysis showed that the presence of liver metastases was an individual risk factor associated with worse overall survival in our patient cohort. Interpretation of the results has to be done with caution because the low number of patients (17 patients at risk in each group) is a severe limitation of the study. Interestingly, the analysis showed that patients with liver metastases hardly ever survived for 20 years compared to $31.0 \%$ of patients without liver metastases.

The sub-analysis comparing overall survival of "surveillance" and "surgery" of liver-metastasis showed a statistically significant impact in favor of surgery (no surgery: $88.1 \pm 8.3$ months vs. surgery: $130.7 \pm 18.5$ months; $p=0.04)$. Interestingly, the short-term overall survival of up to 5-years shows equal results between the two groups (no surgery: $68.8 \pm 6.4 \%$ vs. surgery: $73.9 \pm 10.2 \%$ ). This finding underlines the importance of long-term treatment options in patients with siNENs; because of their very slow growth differences between therapeutic approaches may not be seen before 10-years of followup (no surgery: $24.3 \pm 6.6 \%$ vs. surgery: $60.5 \pm 12 \%$ ). In almost the same manner the conclusion has to be drawn with caution because of a very low number of patients in the 10 year follow up (no surgery: 9, surgery: 6). It needs to be emphasized that this analysis is retrospective and that the treatment plan for each patient was made individually taking into consideration multiple factors that influence the decision whether the patient is a candidate for liver surgery. Therefore, multiple factors must be regarded as a possible bias, i.e. comorbidities that make the patient not fit for liver surgery.

Concerning the extent of liver surgery, no differences in survival were seen between patients with resection of "up to one" or "more liver segments". This may be explained by the extent of liver-disease at the time of surgery which is in the majority of patients more extended than documented by preoperative functional staging. The long term survival of the patients analyzed after 10-years is in concordance with literature [9].

\section{Conclusions}

SiNENs are slowly growing tumors, even in patients with liver metastases the overall survival is very good and not significantly worse compared to patients without liver metastases. However, those patients who received surgery for liver metastases have a better outcome compared to patients whose liver metastases are not removed surgically. This result needs to be interpreted with caution because only patients who are fit for surgery and have metastases that can be sensibly treated by surgery did receive this treatment. Therefore, feasibility to perform surgery on liver metastases in patients with siNENs should be considered especially in patients symptomatic due to high tumor burden and serotonin hypersecretion to reduce hormone activity.

\section{Abbreviations}

5-HT: Serotonin; ENETS: European neuroendocrine tumor society; Ki-67: Kiel67; mTOR: Mechanistic target of rapamycin; NEN: Neuroendocrine neoplasia; NET: Neuroendocrine tumor; RTK: Receptor tyrosine kinase; siNEN: Small intestinal neuroendocrine neoplasia.

\section{Acknowledgements}

Special thanks to the technicians and keepers of the archives at our institution.

Authors' contributions

All authors contributed substantially to this manuscript.

Funding

This study was not funded by a third party.

\section{Availability of data and materials}

All data and material analyzed in this study is available.

\section{Ethical approval and consent to participate}

All procedures performed in this study involving human material were in accordance with the ethical standards of the institutional research committee and with the 1964 Helsinki declaration and its later amendments or comparable ethical standards. Informed consent was obtained from all individual participants included in the study.

\section{Consent for publication}

Consent for publication was obtained from all participants.

\section{Competing interests}

The authors declare that they have no competing interests. 


\section{Author details}

${ }^{1}$ Section "Endocrine Surgery", Division of General Surgery, Department of Surgery, Medical University, Währinger Gürtel 18-20, 1090 Vienna, Austria. ${ }^{2}$ Department of Pathology, Medical University, Währinger Gürtel 18-20, 1090 Vienna, Austria. ${ }^{3}$ Department of Anesthesiology, Medical University, Währinger Gürtel 18-20, 1090 Vienna, Austria.

Received: 11 November 2020 Accepted: 5 January 2021

Published online: 14 January 2021

\section{References}

1. Niederle MB, Hackl M, Kaserer K, Niederle B. Gastroenteropancreatic neuroendocrine tumours: the current incidence and staging based on the WHO and European Neuroendocrine Tumour Society classification: an analysis based on prospectively collected parameters. Endocr Relat Cancer. 2010;17(4):909-18.

2. Selberherr A, Niederle MB, Niederle B. Surgical treatment of small intestinal neuroendocrine tumors G1/G2. Visc Med. 2017;33(5):340-3.

3. Lawrence B, Gustafsson BI, Chan A, Svejda B, Kidd M, Modlin IM. The epidemiology of gastroenteropancreatic neuroendocrine tumors. Endocrinol Metab Clin N Am. 2011;40(1):1-18.

4. Yao JC, Hassan M, Phan A, Dagohoy C, Leary C, Mares JE, et al. One hundred years after "carcinoid": epidemiology of and prognostic factors for neuroendocrine tumors in 35,825 cases in the United States. J Clin Oncol. 2008;26(18):3063-72.

5. Niederle MB, Niederle B. Diagnosis and treatment of gastroenteropancreatic neuroendocrine tumors: current data on a prospectively collected, retrospectively analyzed clinical multicenter investigation. Oncologist. 2011;16(5):602-13.

6. Riihimaki M, Hemminki A, Sundquist K, Sundquist J, Hemminki K. The epidemiology of metastases in neuroendocrine tumors. Int J Cancer. 2016;139(12):2679-86.

7. Jann H, Roll S, Couvelard A, Hentic O, Pavel M, Muller-Nordhorn J, et al. Neuroendocrine tumors of midgut and hindgut origin: tumornode-metastasis classification determines clinical outcome. Cancer. 2011;117(15):3332-41.

8. Sham JG, Ejaz A, Gage MM, Bagante F, Reames BN, Maithel S, et al. The impact of extent of liver resection among patients with neuroendocrine liver metastasis: an international multi-institutional study. J Gastrointest Surg. 2019;23(3):484-91.

9. Manguso N, Nissen N, Hendifar A, Harit A, Mirocha J, Friedman M, et al. Prognostic factors influencing survival in small bowel neuroendocrine tumor with liver metastases. J Surg Oncol. 2019;120(6):926-31.

10. Klimstra DS, La Rosa S, Rindi G. Classification of neuroendocrine neoplasms of the digestive system. Lyon: International Agency for Research on Cancer; 2019.

11. Knigge U, Capdevila J, Bartsch DK, Baudin E, Falkerby J, Kianmanesh R, et al. ENETS Consensus Recommendations for the Standards of Care in Neuroendocrine Neoplasms: Follow-Up and Documentation. Neuroendocrinology. 2017;105(3):310-9.

12. Niederle B, Pape UF, Costa F, Gross D, Kelestimur F, Knigge U, et al. ENETS consensus guidelines update for neuroendocrine neoplasms of the jejunum and ileum. Neuroendocrinology. 2016;103(2):125-38.
13. Tsilimigras DI, Ntanasis-Stathopoulos I, Kostakis ID, Moris D, Schizas D, Cloyd JM, et al. Is Resection of primary midgut neuroendocrine tumors in patients with unresectable metastatic liver disease justified? A systematic review and meta-analysis. J Gastrointest Surg. 2019;23(5):1044-54.

14. Habbe N, Fendrich V, Heverhagen A, Ramaswamy A, Bartsch DK. Outcome of surgery for ileojejunal neuroendocrine tumors. Surg Today. 2013;43(10):1168-74.

15. Capurso G, Rinzivillo M, Bettini R, Boninsegna L, Delle Fave G, Falconi M. Systematic review of resection of primary midgut carcinoid tumour in patients with unresectable liver metastases. Br J Surg. 2012;99(11):1480-6.

16. Caplin ME, Pavel M, Cwikla JB, Phan AT, Raderer M, Sedlackova E, et al. Anti-tumour effects of lanreotide for pancreatic and intestinal neuroendocrine tumours: the CLARINET open-label extension study. Endocr Relat Cancer. 2016;23(3):191-9.

17. Caplin ME, Pavel M, Cwikla JB, Phan AT, Raderer M, Sedlackova E, et al. Lanreotide in metastatic enteropancreatic neuroendocrine tumors. N Engl J Med. 2014;371(3):224-33.

18. Pavel M, O'Toole D, Costa F, Capdevila J, Gross D, Kianmanesh R, et al. ENETS consensus guidelines update for the management of distant metastatic disease of intestinal, pancreatic, bronchial neuroendocrine neoplasms (NEN) and NEN of unknown primary site. Neuroendocrinology. 2016;103(2):172-85.

19. Pavel M, Baudin E, Couvelard A, Krenning E, Oberg K, Steinmuller T, et al. ENETS consensus guidelines for the management of patients with liver and other distant metastases from neuroendocrine neoplasms of foregut, midgut, hindgut, and unknown primary. Neuroendocrinology. 2012;95(2):157-76.

20. Deguelte S, Perrier M, Hammoutene C, Cadiot G, Kianmanesh R. Surgery and perioperative management in small intestinal neuroendocrine tumors. J Clin Med. 2020;9(7):2319.

21. Moris D, Ntanasis-Stathopoulos I, Tsilimigras DI, Vagios S, Karamitros A, Karaolanis G, et al. Update on surgical management of small bowel neuroendocrine tumors. Anticancer Res. 2018;38(3):1267-78.

22. Yuan CH, Wang J, Xiu DR, Tao M, Ma ZL, Jiang B, et al. Meta-analysis of liver resection versus nonsurgical treatments for pancreatic neuroendocrine tumors with liver metastases. Ann Surg Oncol. 2016;23(1):244-9.

23. Hicks RJ, Kwekkeboom DJ, Krenning E, Bodei L, Grozinsky-Glasberg S, Arnold R, et al. ENETS consensus guidelines for the standards of care in neuroendocrine neoplasia: peptide receptor radionuclide therapy with radiolabeled somatostatin analogues. Neuroendocrinology. 2017;105(3):295-309.

24. Pavel M, Valle JW, Eriksson B, Rinke A, Caplin M, Chen J, et al. ENETS consensus guidelines for the standards of care in neuroendocrine neoplasms: systemic therapy - biotherapy and novel targeted agents. Neuroendocrinology. 2017;105(3):266-80.

\section{Publisher's Note}

Springer Nature remains neutral with regard to jurisdictional claims in published maps and institutional affiliations.

Ready to submit your research? Choose BMC and benefit from

- fast, convenient online submission

- thorough peer review by experienced researchers in your field

- rapid publication on acceptance

- support for research data, including large and complex data types

- gold Open Access which fosters wider collaboration and increased citations

- maximum visibility for your research: over 100M website views per year

At BMC, research is always in progress.

Learn more biomedcentral.com/submissions 